\title{
DETERMINAÇÃO DO pH DE UM ARGISSOLO VERMELHO AMARELO distrófico INCUBADO COM APLICAÇÃO DE DOSES CRESCENTES DE $\mathrm{CaCO}_{3}$ POR DIFERENTES MÉTODOS
}

\author{
Luis Felipe Rodrigues de Aquino Sousa ${ }^{1}$; Ricardo Welder Duarte Marinho ${ }^{1}$; Felipe \\ Machado Nunes ${ }^{1}$; Ricardo Vieira Silva ${ }^{1}$; Ivaneide de Oliveira Nascimento ${ }^{1}$; Wilson \\ Araújo da Silva ${ }^{1}$.
}

${ }^{1}$ Universidade Estadual do Maranhão. Imperatriz, Maranhão, Brasil. luis.felipe@msn.com

\begin{abstract}
RESUMO: O objetivo deste trabalho foi determina o $\mathrm{pH}$ de um ARGISSOLO VERMELHO AMARELO distrófico por diferentes métodos após incubação com doses crescentes de $\mathrm{CaCO}_{3}$. O presente trabalho foi realizado no Laboratório de Solos da UEMA/CESI. As amostras de solo foram coletadas em um ARGISSOLO VERMELHO AMARELHO distrófico no Parque de Exposição de Imperatriz/MA, na camada de 0-20 cm de profundidade. Após a coleta das amostras, estas foram conduzidas para o laboratório, secas ao ar, depois destorroados, passadas em peneira de $2 \mathrm{~mm}$ de abertura de malha e homogeneizadas e amostra da para análise química de rotina. As amostras de solo foram postas para incubação doses crescentes de carbonato de cálcio equivalentes a $0,1,2,3,4,5,8$ e 10 t.ha ${ }^{-1}\left(\mathrm{CaCO}_{3}\right)$, com dez repetições, em um delineamento experimental inteiramente casualizado. Após 30 dias o inicio de incubação foi feita amostras de cada unidade experimental para determinar o $\mathrm{pH}$ em água e em $\mathrm{CaCl}_{2}$, a fim de realizar a comparação e correlação destes métodos para o solo estudado. Houve diferença significativa entre os valores de $\mathrm{pH}$ e entre os métodos usados na determinação e intensa mineralização da matéria orgânica.
\end{abstract}

PALAVRAS-CHAVE: água, cloreto de cálcio, correlação.

\section{DETERMINATION OF THE pH OF A Distrophic RED YELLOW ARGISSOL INCUBATED WITH APPLICATION OF INCREASING DOSES OF CACO 3 BY DIFFERENT METHODS}

\begin{abstract}
The objective of this work is to neutralize the effect of exchangeable acidity of a ULTISOL RED YELLOW dystrophic incubated with application of increasing doses of $\mathrm{CaCO}_{3}$. This work was performed at the Laboratory of Soil Science UEMA / CESI. Soil samples were collected in a ULTISOL RED YELLOW dystrophic in Exhibition Park of Imperatriz/MA, at 0-20 cm depth. After collecting the samples, they were carried to the laboratory, air-dried, then broken, passed through a sieve of $2 \mathrm{~mm}$ mesh size and homogenized and sample for chemical analysis routine. Soil samples were placed hatching increasing doses of calcium carbonate equivalent to $0,1,2,3,4,5,8$ and $10 \mathrm{t} / \mathrm{ha}\left(\mathrm{CaCO}_{3}\right)$, with ten repetitions, in a completely randomized design. After 30 days the start of incubation was taken from each experimental samples to determine the $\mathrm{pH}$ in water and $\mathrm{CaCl}_{2}$ in order to perform the comparison and correlation of these methods to study the soil. Significant difference between the $\mathrm{pH}$ values and between the methods used in determining and intense mineralization of organic matter.
\end{abstract}

KEYWORDS: calcium chloride, correlation, water. 
A maioria dos solos brasileiros apresenta limitações ao estabelecimento e desenvolvimento dos sistemas de produção de grande parte das culturas, em decorrência dos efeitos da acidez (NOVAIS et al., 2007). Portanto, a maioria dos solos brasileiros necessita de correção de sua acidez, o que normalmente é feita através da adição de calcário, pratica esta conhecida por calagem (VITTI; LUZ, 2004).

A calagem é importante prática agrícola para a correção da acidez dos solos (RAIJ, 2008). A aplicação de corretivos em solos ácidos eleva o $\mathrm{pH}$, aumenta as cargas negativas no complexo de troca e diminui a solubilidade do alumínio e do ferro, aumentando, por isso, a disponibilidade de fósforo na solução do solo e a retenção de cátions (CHAVES; FARIAS, 2008).

Com as curvas de calibração, pode-se determinar a dosagem de calcário necessária para atingir um determinado $\mathrm{pH}$ requerido por uma cultura (QUAGGIO, 2000; RAIJ et al., 1996; RIBEIRO et al., 1999; SOUSA; LOBATO, 2004).

Este método apresenta algumas inconveniências. Pode haver mineralização intensa da matéria orgânica durante a incubação, resultando na superestimação da necessidade de calcário.
Adicionalmente, em decorrência do aumento dos sais solúveis que influenciam a força iônica da solução, é possível ocorrer erros na determinação do $\mathrm{pH}$ em água. O problema do excesso de sais pode ser contornado pela determinação do $\mathrm{pH}$ em solução de $\mathrm{CaCl}_{2} 1 \mathrm{mmol} \mathrm{L}{ }^{-1}$, de força iônica constante (NOVAIS et al., 2007).

O objetivo deste trabalho foi determinar o pH de um ARGISSOLO VERMELHO AMARELO distrófico por diferentes métodos após incubação com doses crescentes de $\mathrm{CaCO}_{3}$.

O presente trabalho foi realizado no Laboratório de Solos da Universidade Estadual do Maranhão (UEMA), Centro de Estudos Superiores de Imperatriz (CESI).

As amostras de solo foram coletadas em um ARGISSOLO VERMELHO AMARELHO distrófico no sudoeste do Estado do Maranhão no Parque de Exposição de Imperatriz, pertencente ao SINRURAL, na camada de 0-20 cm de profundidade.

Após a coleta das amostras, estas foram conduzidas para o laboratório, secas ao ar, depois destorroados, passadas em peneira de $2 \mathrm{~mm}$ de abertura de malha e homogeneizadas e amostra da para análise química de rotina de acordo com a metodologia proposta pela Embrapa (1997) (Tabela 1). 
Tabela 1. Análise química do solo amostrado.

\begin{tabular}{|c|c|c|c|c|c|c|c|c|}
\hline \multirow{2}{*}{ pH em água } & $\mathrm{Ca}^{2+}+\mathrm{Mg}^{2+}$ & $\mathrm{Al}^{3+}$ & $\mathrm{H}+\mathrm{Al}$ & SB & CTC & $\mathrm{V}$ & $\mathrm{K}$ & $P$ \\
\hline & & $\ldots \ldots$. & $\mathrm{l}_{\mathrm{c}} \cdot \mathrm{kg}^{-1}$ & & & $\ldots \% \ldots$ & ......mg. $\mathrm{kg}^{-1}$ & \\
\hline 5,61 & 4,96 & 1,2 & 6,5 & 6,16 & 11,6 & 43,9 & 50 & 8 \\
\hline
\end{tabular}

As amostras de solo foram postas para incubação com diferentes quantidades de carbonato de cálcio $\left(\mathrm{CaCO}_{3}\right)$. Os tratamentos consistiram em oito doses crescentes de carbonato de cálcio equivalentes a $0,1,2,3,4,5,8$ e $10 \mathrm{t} / \mathrm{ha}$ $\left(\mathrm{CaCO}_{3}\right)$, com dez repetições, em um delineamento experimental inteiramente casualizado, cada unidade representada por $0,3 \mathrm{~kg}$ do solo.

As doses crescentes de $\mathrm{CaCO}_{3}$ foram adicionadas nas sua respectivas unidades experimentais, homogeneizadas e armazenados em recipientes plásticos com capacidade para $0,4 \mathrm{~kg}$. A umidade do solo em cada unidade experimental foi mantida em $80 \%$ da capacidade de campo adicionando-se água destilada e mantida por todo período de incubação, fechados com tampas perfuradas e com um canudo, de modo a permitir que o solo realizasse suas trocas gasosas, distribuídos numa bancada ao abrigo da luz.

Aos 30 dias após o inicio de incubação foi feita amostras de cada unidade experimental para determinar o $\mathrm{pH}$ em água e em $\mathrm{CaCl}_{2}$ de acordo com métodos da Embrapa (1997), a fim de determinar a correlação entre os valores. Foi feita ainda análise de variância e de regressão.

Para $\mathrm{pH}$ em água houve uma diferença significativa entre as medias dos tratamentos e um baixo coeficiente de variação.

Com os dados foi possível constatar que com a adição de 1 t.ha ${ }^{-1}$ de $\mathrm{CaCO}_{3}$ foi possível elevar o $\mathrm{pH}$ do solo determinado em água para uma faixa desejável na agricultura, em torno de 6,0 a 6,5. Já quando se determinou o $\mathrm{pH}$ em $\mathrm{CaCl}_{2}$ a quantidade necessária para atingir a mesma faixa foi de $2 \mathrm{t}$. ha ${ }^{-1}$ de $\mathrm{CaCO}_{3}$ (Figuras 1 e 2).

Também foi observado que para todos os tratamentos as medias de $\mathrm{pH}$ em água e $\mathrm{CaCl}_{2}$ diferiram estatisticamente mesmo com o poucos dias de incubação (Tabela 2). O mesmo resultado também é observado por Silva el al. (2008) e Nicolodi et al. (2008) para amostras de ORGANOSSOLOS e LATOSSOLO VERMELHO distrófico respectivamente. 


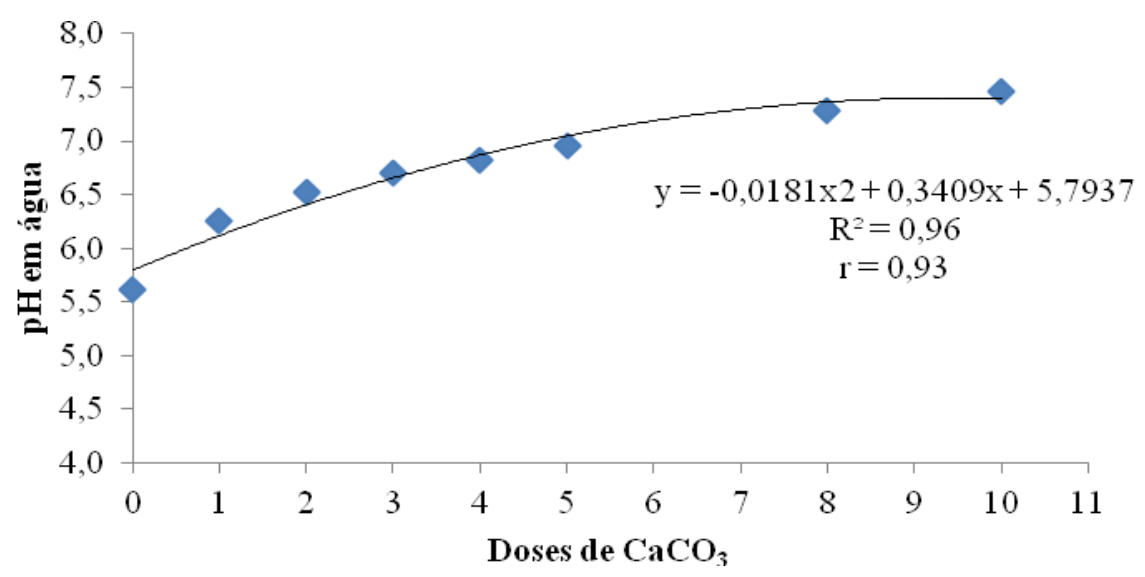

Figura 1. Curva de neutralização do solo após 30 dias do início da incubação, relação entre doses de $\mathrm{CaCO}_{3}$ e pH determinado em água.

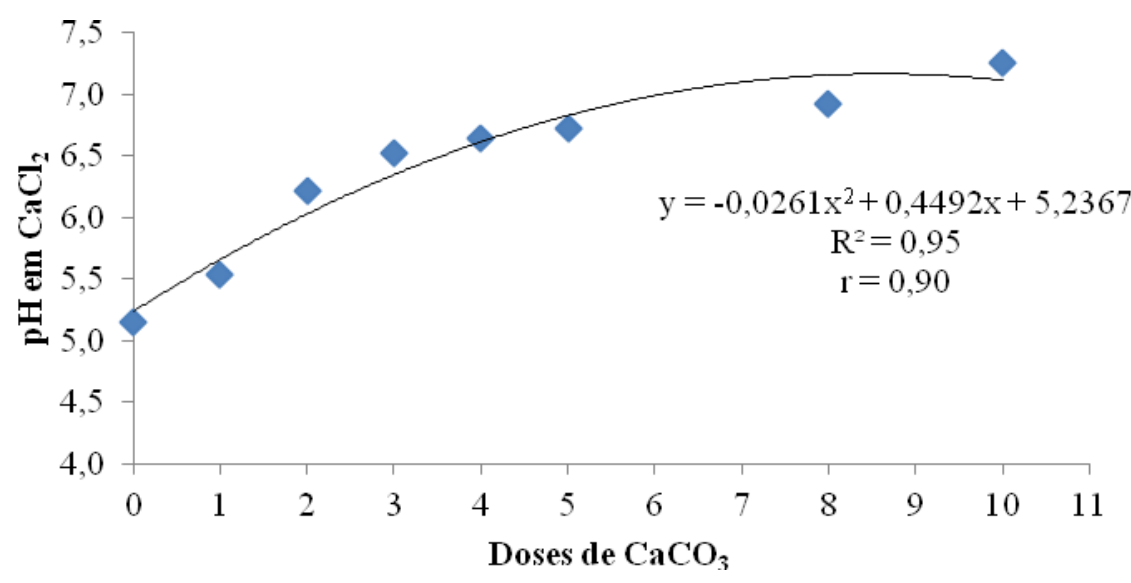

Figura 2. Curva de neutralização do solo após 30 dias do início da incubação, relação entre doses de $\mathrm{CaCO}_{3}$ e $\mathrm{pH}$ determinado em $\mathrm{CaCl}_{2}$.

Tabela 2. Médias de $\mathrm{pH}$ em água e $\mathrm{CaCl}_{2}$ do solo em relação às doses de $\mathrm{CaCO}_{3}$ aplicado após 30 dias do início do período de incubação.

\begin{tabular}{|c|c|c|c|c|c|c|c|c|}
\hline \multirow[b]{2}{*}{$\mathrm{pH}$} & \multicolumn{8}{|c|}{ Doses de $\mathrm{CaCO}_{3}$ t.ha ${ }^{-1}$} \\
\hline & 0 & 1 & 2 & 3 & 4 & 5 & 8 & 10 \\
\hline em água & $5,61 \mathrm{Af}$ & $6,26 \mathrm{Ae}$ & 6,53 Ad & 6,71 Acd & 6,82 Abc & $6,96 \mathrm{Ab}$ & 7,29 Aa & 7,46 Aa \\
\hline em $\mathrm{CaCl}_{2}$ & $5,15 \mathrm{Bg}$ & $5,54 \mathrm{Bf}$ & $6,22 \mathrm{Be}$ & $6,52 \mathrm{Bd}$ & $6,64 \mathrm{Bcd}$ & $6,72 \mathrm{Bc}$ & $6,93 \mathrm{Bb}$ & 7,26 Ba \\
\hline DMS & 0,202 & 0,121 & 0,056 & 0,056 & 1,000 & 0,041 & 0,042 & 0,100 \\
\hline $\mathrm{CV} \%$ & 4,00 & 2,18 & 0,94 & 0,91 & 1,58 & 0,63 & 0,62 & 1,45 \\
\hline
\end{tabular}

Médias seguidas de letra maiúscula nas colunas e minúsculas nas linhas, não diferem entre si estatisticamente, a $1 \%$ de probabilidade, pelo teste de Tukey. 
A diferença entre os valores de $\mathrm{pH}$ determinado em água e $\mathrm{CaCl}_{2}$ se da pelo fato de que a mineralização da matéria orgânica é muito grande e muitas das vezes, como neste caso, em decorrência do aumento dos sais solúveis que influenciam a força iônica da solução mascara o resultado real das análise, resultando na superestimação da necessidade de calcário conforme relatado por Novais et al. (2007).

Verificou-se que houve diferença significativa entre os valores de $\mathrm{pH}$ e entre os métodos usados na determinação.

A matéria orgânica teve influencia no poder tampão do solo, em virtude de sua alta mineralização, assim diferindo nos valores de $\mathrm{pH}$ determinado por água e $\mathrm{CaCl}_{2}$.

\section{REFERÊNCIAS}

CHAVES, L. H. G.; FARIAS, C. H. A. Escória de siderurgia e calcário na correção da acidez do solo e na disponibilidade de cálcio, magnésio e fósforo. Revista Caatinga, Mossoró, v. 21, n. 5, p. 75-82, dez, 2008.

EMPRESA BRASILEIRA DE PESQUISA AGROPECUÁRIA - EMBRAPA.

Manual de métodos de análises de solo.

2.ed. Rio de Janeiro, Ministério da Agricultura e do Abastecimento, 1997. 212 .
NICOLODI, M.; ANGHINONI, I.; GIANELLO, C. Relações entre os tipos e indicadores de acidez do solo em lavouras no sistema plantio direto na região do Planalto do Rio Grande do Sul. Rev. Bras. Ciênc. Solo, Viçosa, v. 32, n. 3, mai-jun. 2008 .

NOVAIS, R.F.; ALVAREZ V., V. H.; BARROS, N. F.; FONTES, R. L. F.; CANTARUTTI, R. B.; NEVES, J. C. L. (Eds.) Fertilidade do solo. Viçosa: SBCS, 2007. 1017 p.

QUAGGIO, J.A. Acidez e calagem em solos tropicais. Campinas: Instituto Agronômico de Campinas, 2000. 111p.

RAIJ, B. van. Gesso na agricultura. Campinas: Instituto Agronômico, 2008. $233 p$.

RAIJ, B. van; CANTARELLA, H. QUAGGIO, J. A.; FURLANI, A. M. C., eds. Recomendação de adubação e calagem para o Estado de São Paulo. $2^{\text {a }}$ ed. Campinas, Instituto Agronômico de Campinas, 1996. 285p. (Boletim Técnico, 100).

RIBEIRO, A. C; GUIMARÃES, P.T.G.; ALVAREZ V., V. $\quad$ H., (Eds.) Recomendação para uso de corretivos e fertilizantes em Mina Gerais: $5^{\circ}$ aproximação. Viçosa, MG, CFSEMG, 1999. 359 p. 
SILVA, E. B; SILVA, A. C.; GRAZZIOTTI, P. H; FARNEZI, M. M. M.; FERREIRA, C. A.; COSTA, H. A. O.; HORAK, I. Comparação de método para estimar a acidez potencial mediante determinação do $\quad \mathrm{pH} \quad \mathrm{SMP}$ em ORGANOSSOLOS da Serra do Espinhaço Meridional. Rev. Bras. Ciênc.

Solo, Viçosa, v. 32, n. 5, set-out. 2008.

SOUSA, D. M. G.; LOBATO, E. Cerrado: Correção do solo e adubação.

2.ed. Brasília, Embrapa Informação Tecnológica, 2004. 416p.

VITTI, G. C.; LUZ, P. H. Utilização agronômica de corretivos agrícolas.

Piracicaba: FEALQ, 2004. 120p. 